\title{
UNBEKANNTE BRÜNNER ORATORIEN NEAPOLITANISCHER KOMPONISTEN VOR 1740
}

Die Stadt Brünn hat in den 20er und 30er Jahren des 18. Jahrhunderts eine große Blüte hinsichtlich der Aufführungen italienischer Oratorien erlebt. ${ }^{1}$ Über diese außerordentliche Regsamkeit berichten vornehmlich die überlieferten Libretti, gegenwärtig sind 49 Brünner Oratorien bekannt. Die Aufführungssprache war zumeist italienisch, doch die Textbücher enthalten in der Regel auch eine Synopsis in Deutsch. Allerdings konnten auch 10 Oratorien mit deutschem Originaltext nachgewiesen werden. Was das musikalische Material betrifft, so wurden bisher drei Partituren (1730 Morte e sepoltura di Christo, 1730 Il trionfo della croce, 1732 Il martirio di S. Giovanni Nepomuceno) und ein Fragment (1726 Il peccato di Adamo) aufgefunden. Brünn übertraf in dieser Hinsicht sehr wohl andere Musikzentren Mährens. Aus Olmütz beispielsweise sind lediglich 7 deutsche Oratorien-Libretti bekannt, ein italienisches Oratorium wurde 1736 in Holleschau gespielt, aus Znaim ist dann ein 1734 datiertes deutsches Oratorium bekannt. (Siehe Beilage 3). ${ }^{2}$

Ein bedeutender Initiator dieser Produktionen war der Bischof von Olmütz und ehemaliger Vizekönig des Königreiches Neapel Wolfgang Hannibal Kardinal von Schrattenbach (1660-1738), von den erwähnten 49 Brünner Oratorien wurden 34 von ihm angeregt. ${ }^{3}$ Als hochverdiente Mäzene sind auch der Graf Johann

1 Der vorliegende Artikel entstand mit finanzieller Unterstützung seitens des Kulturministeriums der Tschechischen Republik im Rahmen der institutionellen Finanzierung der langfristigen konzeptionellen Entfaltung von Fortschungsinstitutionen (Mährisches Landesmuseum, MK000094862). spěvek k poznání hudebního života na Moravě. Opus musicum, 2012, 44, Nr. 3, S. 6-13. Př́spěvek $k$ libretistice barokni opery a oratoria. Diss. FF MU Brno, 2006. Hier befindet sich auch ein Katalog der Oratorienlibretti einschliesslich eines Incipitkatalogs der Arien. Zugänglich auf: http://is.muni.cz/th/82417/ff_d. Neuere Studien, vornehmlich zum nachträglich identifizierten Musikmaterial: SPÁČILOVÁ, Jana: Nové poznatky k hudbě na dvoře olomouckého biskupa Schrattenbacha. Musicologica Brunensia, 2010, Nr. 1-2, S. 198-206; SPÁČILOVÁ, Jana: Die Rezeption der italienischen Oper am Hofe des Olmützer Bischofs 
Adam Questenberg (1678-1752) und der Brünner Probst und Olmützer Domherr Johann Matthias Thurn-Valsassina (1683-1746) hervorzuheben.

Der Graf Questenberg ließ in Brünn vornehmlich in der Kapuzinerkirche Oratorien aufführen, es sind drei Libretti seines Kapellmeisters Franz Anton Mitscha bekannt (1730 Die Beschuldigte Unschuld, 1731 Öfterer Anstoß, 1734 Die Heil. Helena auf dem Calvari-Berg). In der Fastenzeit des Jahres 1736 ließ er seine Musiker zwei italienische Oratorien aufführen, und zwar Caldaras Sant'Elena al Calvario (in der St. Jakobs-Kirche) und Il martirio della Madre de'Macabei von Francesco Bartolomeo Conti (in der St. Michaels- Kirche, es handelte sich um eine Reprise des 1732 in Wien unter dem Titel L'osservanza della divina legge nel martirio de'Macabei gespielten Werkes). ${ }^{4}$ Diesen Kompositionen ist der Beitrag von Jana Perutková in diesem Band gewidmet, daher soll hier der letztgenannte Mäzen, Johann Matthias Thurn-Valsassina, nur kurz erwähnt werden.

Über seine musikalischen Vorlieben informiert uns sein Nachlassverzeichnis aus dem Jahre 1747. ${ }^{5}$ Das Inventar verzeichnet mehrere Dutzend Musikinstrumente sowie an die 400 Werke, darunter auch 18 Oratorien. Als deren Autoren figurieren vor allem die einheimischen Komponisten Mitscha (drei deutsche und ein italienisches Oratorium), Orschler (zwei deutsche und ein italienisches Oratorium) und Guretzky (ein deutsches Oratorium). Mit je einer Oratorien-Partitur sind Conti, Pergolesi, Camilla de Rossi, Michele Fini und ein „Finazzoli“ (wahrscheinlich eine Verwechslung mit Agostino Tinazzoli) genannter Komponist vertreten. ${ }^{6}$ Ein Werk wird lediglich unter dem Titel La morte d'Abele verzeichnet, es mag sich um die heute in der Musiksammlung des Schlosses Kremsier aufbewahrte anonyme Quelle handeln. ${ }^{7}$

Ein nicht näher bezeichnetes „Oratorio von Francesco Conti“ bezieht sich wahrscheinlich auf Contis 1726 in Olmütz aufgeführtes Johannes von NepomukOratorium (siehe weiter). Auch die nächste Eintragung ließe sich wohl auf eine konkrete Aufführung beziehen. Es handelt sich um das „Oratorium von der gött-

Schrattenbach. In The Eighteenth-Century Italian Opera Seria: Metamorphoses of the Opera in the Imperial Age [Colloquia Musicologica Brunensia, 42, 2007], Praha: KLP, 2013, S. 75-88.

4 PERUTKOVÁ, Jana. František Antonín Míča ve službách hraběte Questenberga a italská opera v Jaroměricich, Praha: KLP, 2011, insbesondere S. 54-55. Zur Autorschaftsbestimmung des Caldara-Oratoriums vgl. SPÁČILOVÁ, Jana. Sant'Elena al Calvario: Leo, Míča, Caldara nebo Conti? Příspěvek k historii oratoria v českých zemích doby baroka. Opus musicum, 2009, 41, Nr. 3, S. 25-29.

5 SEHNAL, Jiří. Nové poznatky k dějinám hudby na Moravě v 17. a 18. století. Časopis Moravského musea, 1975, 60, S. 159-180.

6 Dieselbe Verwechslung des Komponistennamens gibt es auch im Inventar der Sammlung der Dresdner Hofkirche aus dem Jahre 1765, vgl. STOCKIGT, Janice. Italian Composers Listed in the „Catalogo 1765“ („Schürer-Katalog“) of the Dresden Hofkirche. Pergolesi Studies, 2012, 8, S. 171-198.

7 Stimmen CZ-KRa A2334 (I-C-9), im Katalog der Bibliothek als Cain et Abel geführt. Der Titel La Morte d'Abele und der Librettist Pietro Metastasio konten durch Textanalyse ermittelt werden, der Komponist ist unbekannt. 
lichen Liebe von Wencel Guretzky“, das, wenn man vom Namen der Hauptgestalt ausgeht, mit dem 1740 in der Brünner Jakobskirche gespielten Werk Der durch die Gerechtigkeit verdammte und von der Göttlichen Liebe erlöste Sünder identisch sein könnte. ${ }^{8}$ Es wird jedoch weder der Autor, noch der Auftraggeber angeführt, daher kann diese Annahme einstweilen nicht bestätigt werden.

Im Zusammenhang mit der Rezeption des italienischen Oratoriums in Mähren ist weiterhin die Aufführung von Antonio Caldaras S. Giovanni Battista auf den Gütern des Grafen Rottal in Holleschau im Jahre 1736 zu vermerken, das einst in der Bibliothek des Schlosses von Kremsier aufbewahrte Libretto ist heute leider verschollen. ${ }^{9}$ Die ebenfalls unerfindliche Partitur ist offenbar auch Bestandteil der Sammlung von Kremsier geworden, ein ungenanntes Oratorium von Caldara wird nämlich in der Rubrik ,etl[iche] alte [Partituren] von S. Exc. Graf Rottal" im Nachlassinventar des Olmützer Erzbischofs Leopold Egkh aus dem Jahre 1761 angeführt. ${ }^{10}$

\section{Mährische Oratorien der Wiener Hofkomponisten}

Eine bedeutende Gruppe des mährischen Repertoires bilden deutsche Oratorien der Wiener Komponisten Johann Georg Reinhardt, Giuseppe Porsile und Francesco Bartolomeo Conti. Reinhardt wird als der Autor des überhaupt ersten Brünner Oratoriums genannt. Es hieß Desperati peccatori a moriente Jesu restituta vita, das ist: Das durch den Todt Jesu dem verzweifflenden Sünder wider beygebrachte Leben, und wurde in der heute nicht mehr existierenden St. Nicolaus-Kirche am Karfreitag 1721 gespielt. ${ }^{11}$ Einen nahezu gleichen Titel (Per crucem Jesu fit desperanti vitae restitutio das ist: Das durch das Creutz Jesu dem verzweiffelten Sünder wieder beygebrachene Leben) trägt ein anderes, am Gründonnerstag 1726 bei den Kapuzinern in Olmütz aufgeführtes Oratorium. ${ }^{12}$ Wenngleich sich auf dem Titelblatt ein Hinweis auf mehrfache Aufführung (,wiederhollet") befindet, handelt es sich nicht um dasselbe Stück. ${ }^{13}$ Die Zahl der handelnden Personen ist unterschiedlich, auch ihre Namen sind anders und die Texte decken sich

$8 \quad$ Libretto Cz-Pnm B 4157.

9 Ursprüngliche Signatur: Z/a/XII, přív.8. SEHNAL, Jiří. Hudební literatura zámecké knihovny v Kroméřziži. Gottwaldov, 1960, S. 162.

10 Fotokopie des Inventars CZ-Bm G 579. SEHNAL, Jiří. Kapela olomouckého biskupa Leopolda Egka (1758-1760) a její repertoár. Časopis Moravského musea, 1965, 50, S. 203-230.

11 Libretto Cz-R Z.f.18, př. 9.

12 Libretto GB-Lbl T.1857.(4.) Für die Besorgung der Kopie gehört mein herzlicher Dank Herrn Petr Slouka.

13 Das Identischsein beider Oratorien wird - irrümlich - mehrfach in der Literatur erwähnt, zuletzt bei SPÁČILOVÁ, Jana. Kirchenmusik Wiener Komponisten in Mähren in der ersten Hälfte des 18. Jahrhunderts. In Sakralmusik im Habsburgerreich 1570-1770, Wien, 2013, S. 285-300. 
ebenfalls nicht. ${ }^{14}$ Im Jahre 1730 brachte man in Brünn bei St. Jakob ein drittes „mährisches" Oratorium von J. G. Reinhardt, sein Testamentum Salvatoris, das ist: Der letzte Willen des Erlösers unsers Herrns Jesu Christi. ${ }^{15}$ Als Auftraggeber des Werkes wird der „Magistrat der königlichen Stadt Brünn“ angegeben. In Anbetracht der nachgewiesenen Kontakte des Wiener Hoforganisten zu Mähren (Reinhardt war im Kontakt mit dem Prämonstratenserkloster Hradisko bei Olmütz, das er 1718 wahrscheinlich auch besucht hatte) ist es sehr wahrscheinlich, dass er die genannten Werke direkt auf Bestellung des mährischen Adels schuf. ${ }^{16}$

Aus der Feder des Hofkomponisten Giuseppe Porsile stammt das Johannes von Nepomuk-Oratorium Ruhmwürdiger Cron- und Ehrenstreit, anlangend den grossen Heiligen Stummen Wohlredner und wohlredenten Stummen S. Joannem Nepoтисепum, das in der Brünner St. Peter und Paulskirche am Petersberg zum Fest dieses Heiligen am 16. Mai 1724 gegeben wurde. ${ }^{17}$ Das Libretto ist ein Beleg für einen bereits vor der Heiligsprechung des Johannes im Jahre 1729 in den böhmischen Ländern bestehenden Nepomuk-Kult. ${ }^{18}$

Johannes von Nepomuk ist auch das 1726 in der Olmützer Maria Schnee Kirche aufgeführte Oratorium Unüberwindliche Verschwiegenheit des wunderthätigen Blut-Zeugen Christi S. Joannis von Nepomuck ${ }^{19}$ von Francesco Bartolomeo Conti gewidmet. Dieser Komponist hatte enge Beziehungen zu den böhmischen Ländern, der Hauptpropagator seiner Musik war Graf Johann Adam Questenberg. Hinter dem Olmützer Nepomuk-Oratorium mag jedoch eher Johann Matthias Thurn-Valsassina gestanden haben. ${ }^{20}$

141721 Rollen: Der Catholische Kirchen-Gebrauch - Die Erinnerung deß Leydens Christi Das Mitleyden der Gerechten - Die Hoffnung deß ewigen Lebens - Die Forcht Göttlicher Gerechtigkeit - Der Anfangs Boßhaffte, zu letzt aber Bekehrte Sünder, Textincipit: „Wach auff verstockter Mensch, verlaß das Beth der Sünden“; 1726 Rolen: Die Göttliche Lieb - Die Göttliche Gnad - Die Allmacht Gottes - Der gerechte Mensch - Der Gottlose Sünder, Textincipit: „Wer kan mich von meiner Peyn“.

15 Libretto Cz-R Z.f.18, př. 10.

16 Zur Reinhardts Beziehung zu den Prämonstranensern von Hradisko vgl. SEHNAL, Jiří. Hudba v premonstrátském klášteře Hradisko u Olomouce. Časopis Moravského musea, 1991, 76, S. 185-222, insbesondere S. 213.

17 Libretti Cz-R C.II.cc.12, C.II.dd.18, př. 2, P.f.48, př.4; Cz-OLu II.8.535, II 23.124.

18 Vgl. SPÁČILOVÁ, Jana. Das „Oratorio di S. Giovanni Nepomoceno“ von Antonio Caldara im Kontext der Nepomuk-Oratorien in den 20er Jahren des 18. Jahrhunderts. Musicologica Austriaca, 2009, 28, S. 145-160.

19 Libretto CZ-OLu 600.820.

$20 \mathrm{Zu}$ den Kontakten von F. B. Conti und seinem Sohn Ignazio Conti mit den böhmischen Ländern siehe SPÁČILOVÁ, Jana. Contiho moteto k poctě svatých Cyrila a Metoděje. Vlastivědný věstník moravský, 2013, 65, Nr. 2, S. 140-146. 


\section{Oratorienwerke von Johann Georg Orschler und Joseph Umstatt}

Mit zwei Oratorien hatte Johann Georg Orschler (1698-ca. 1770), ein beachtenswerter, in böhmischen Ländern tätiger Komponist schlesischer Herkunft, zum Brünner Repertoire beigetragen. Orschler (u. A. auch Orsler geschrieben), wurde in Breslau geboren und als Pagenknabe des Grafen Zierotin zur Ausbildung nach Wien geschickt, wo er bei Rosetti und Fux studierte. In den Jahren 1726-1727 wird er als „,musicus“ in Prag verzeichnet und einiges spricht auch für seinen Besuch in Dresden, wo sich seine Kompositionen erhalten haben. ${ }^{21} \mathrm{Ab}$ 1730 hielt er sich wahrscheinlich in Mähren auf und stand in nicht näher spezifizierter Beziehung zu Johann Matthias Thurn-Valsassina. Über diesen Musiker heißt es Johann Georg Walthers 1732 herausgegebenem Lexikon, er ,hält sich jetzo bey einem gewissen Grafen in Ollmütz auf", wobei dieser Graf entweder Thurn-Valsassina, oder bereits der Graf Rottal, in dessen Diensten Orschler in den Jahren 1731-1736 als ,aulae prefectus“ tätig war, gewesen sein kann. Ab 1748 wird Orschler als Kapellmeister der Fürsten Liechtenstein geführt, ${ }^{22}$ später siedelte er nach Wien um, wo er im Zeitraum 1753-1766 unter anderem für den Grafen Collalto arbeitete. ${ }^{23}$

Orschlers erstes „mährisches“ Werk war Ein andächtig-verfastes Oratorium Zu Ehren des grossen Blut-Zeugens Christi Heil: Joannis von Nepomuck, aufgeführt in Brünn am Petersberg „,aus Anordnung Joannis Mathiae Graffen von Thurn und Vallesassina" anlässlich der Heiligsprechungsfeierlichkeiten am 17. 9. $1730 .^{24}$ Der Komponist wird nicht genannt, lässt sich jedoch aufgrund des Librettos zum gleichen Oratorium, das ein Jahr später in Olmütz, wo Thurn-Valsassina Domherr war, gespielt wurde, bestimmen. Auf dem Titelblatt des Olmützer Oratoriums wird der Auftraggeber nicht vermerkt, man muss jedoch hinsichtlich seiner Person keinerlei Zweifel hegen. Die Angabe über den Komponisten lautet: „Die Musique hat componirt Herr Johann Georg Orschler". ${ }^{25}$ Der Librettist wird nicht genannt, doch aufgrund der im Kopfteil gedruckten Namen der handelnden Personen (Hermenegildus - Ingonda - Leovigildus - Consiliarus - Leander) lässt sich das Libretto auf das in der Fastenzeit des Jahres 1727 in Brünn aufgeführtes Oratorium Santo Ermengildo beziehen. Die Textanalyse hat ergeben, dass es sich um seine fast wörtliche Übersetzung dieses Oratoriums handelt, wobei Hermengildus zum Johannes von Nepomuk geworden war, seine Gattin, die französissche

$21 \mathrm{Zu}$ Orschlers Aufenthalt in Prag siehe insbesondere KAPSA, Václav. Hudebníci hraběte Morzina. Přrispěvek $k$ dějinám šlechtických kapel v Čechách v době baroka. Praha: Kabinet hudební historie EÚ AV ČR, 2010, S. 108. dies in Music History presented to H. C. Robbins Landon on his 70. Birthday, London, 1996, S. 195-217, hier auf S. 214.

23 STRAKOVÁ, Theodora. Hudebníci na collaltovském panství, Časopis Moravského musea, 1966, 51, S. 231-268, hier auf S. 248. 
Prinzessin Igonda, wandelte sich zur Königin Johanna, aus dem Gotenkönig und Hermengildus Vater Leovigildus wurde der König Wenzel IV., aus dem Bischof Leander ein in der Person des „Podivinus“ (,Wunderling“) auftretender Engel. Die einzig unveränderte Person blieb der Ratgeber („Consiliarius“). Santo Ermegildo erlebte seine Premiere im römischen Seminarium Romanum im Jahre 1725, die Musik stammte von dem Nepolitanischen Komponisten Domenico Sarro, der Librettist ist unbekannt.

In der Fastenzeit des Jahres 1733 wurde bei den Kapuzinern in Brünn ein weiteres Oratorium von Orschler, Die Beschuldigte Unschuld, gespielt. ${ }^{26}$ Es handelt sich um einen vermutlich 1728 entstandenen Text, der bereits 1730 von Franz Anton Mitscha vertont wurde. ${ }^{27}$ Diese beiden deutschen Oratorien Orschlers entsprechen den im Nachlassschrift von Thurn-Valsassina aus dem Jahre 1747 verzeichneten Werken, ein drittes, ebendort eingetragenes italienisches Oratorium, konnte bisher nicht identifiziert werden.

Zwei Oratorien von Joseph Umstatt (1711-1762) sind zwar erst nach 1740 entstanden, wir haben es hier mit nicht allzu bekannten Quellen zu tun, die das Werkverzeichnis dieses beachtenswerten Komponisten ergänzen und darüber hinaus gerade im Hinblick auf die Durchdringung der weltlichen und geistlichen Musik äußerst interessant sind. Der gebürtige Wiener studierte in den Jahren 1727-1730 bei den Jesuiten in Tyrnau, 1730-1739 wirkte er in der Kapelle des Bischofs Imrich Esterházy in Preßburg. ${ }^{28} 1740$ war er wahrscheinlich in Wien, worauf der in der Österreichischen Nationalbibliothek aufbewahrte Autograph seiner Violinkonzerte hindeutet. ${ }^{29}$ Spätestens im Oktober 1741 trat er in die Dienste von Johann Leopold Dietrichstein, wo er zumindest bis 1748 als Kapellmeister tätig war. ${ }^{30}$ Belege für Umstatts Wirken in Dietrichsteins Diensten liefern nicht nur die Matrikeln, sondern bespielsweise auch die in der Bibliothek des Prager Konservatoriums deponierte Sinfonie a quadro, wo er als ,Sig:re Umstatt Compositeur de Son Altesse Mgr le Prince de Dietrichstein" auf dem Titelblatt verzeichnet wird. ${ }^{31}$

26 Libreto Cz-R Z.f.18, př. 7.

27 Näheres zu dieser Problematik siehe Beiträge von Jana Perutkové a Ladislav Kačic im vorliegenden Sammelband.

28 KAČIC, Ladislav. Joseph Umstatt (1711-1762) zwischen Barock und Klassik: Bemerkungen zur Stilentwicklung eines mitteleuropäischen Komponisten. In Zur Geschische und Aufführungspraxis der Musik des 16.-18. Jahrhunderts in Mittel- und Osteuropa. Bratislava, 2013, S. 201-215.

29 A-Wn Mus. Hs. 15566. Joseph Umstatt: Concerti per Violino. Hrsg. von Ladislav Kačic, Bratislava, 2013.

30 SEHNAL, Jiř́. Die adeligen Musikkapellen (zitiert in der Anm.), S. 201-202. Bezüglich der Tätigkeit Umstatts bei Dietrichstein verweist Sehnal auf die Matrikeln der Brünner St. Jakobs-Kirche, wo der Name des Komponiste erstmalig am 23.10. 1741 verzeichnet wird (Mährisches Landesarchiv Brno, St. Jakobs-Kirche Brno, Geburtsmatrikel, Nr. 16864, S. 177, Eintragung über die Taufe der Tochter des Trompeters Karl Harbig, der Pate war „D. Joseph: Umstatt Capell-Meister apud Excell. D. D. Comitem Dittrichstein").

31 CZ-Pk 5789, www.rism.info, ID no. 550280187. 
In der Fastenzeit des Jahres 1741 hörte man in Brünn das Oratorium La vittima d'amore osia La morte di Christo Signor Nostro, es war das erste Werk, mit dem sich Umstatt in seinem neuen Wirkungsort Brünn vorgestellt hatte. ${ }^{32}$ Das Oratorium war bis dahin lediglich von seiner Aufführung bei den Prager Kreuzherren in der Fastenzeit des Jahres 1744 her bekannt, seine Entstehung muss jedoch um drei Jahre zurückdatiert werden. ${ }^{33}$ Die Prager Version entspricht wörtlich dem Brünner Libretto, über die Aufführung des Oratoriums exisiert sogar ein Vermerk im Kreuzherreninventar: „1744. La Vittima d'amore. Auth. Vmstadt apud Principem Dittrichstein in Moravia Capellae Magistro". ${ }^{34}$ Robert Eitner verzeichnet in seinem Quellenlexikon eine in der Bibliothek der Leipziger Thomasschule befindliche Partitur, die heute jedoch verschollen ist. ${ }^{35}$

Der Text geht auf ein älteres Libretto von Francesco Torti zurück (erste Vertonung 1690), bei einer näheren Untersuchung stellen wir jedoch fest, dass Umstatt das Werk zumindest teilweise als ein aus weltlichen und geistlichen Stücken zusammengefügtes Pasticcio schuf. Bis jetzt wurde die Arie Gelido in ogni vena aus Metastasios Libretto Siroe, Re di Persia, das als Erster 1726 Leonardo Vinci in Venedig vertonte, identifiziert. Vor 1741 wandte sich eine ganze Reihe weiterer Komponisten dem Siroe-Libretto zu (Porta, 1726; Porpora, 1727; Sarri, 1727; Vivaldi, 1727; Handel, 1728; Fiorè, 1729; Bioni, 1732; Hasse, 1733; Latilla, 1740; Perez, 1740), abgesehen von der Verwendung der besagten Metastasio-Arie in nicht mehr feststellbarer Zahl weiterer Opern. Eine der berühmtesten Vertonungen von Gelido in ogni vena stammt aus der Feder von Antonio Vivaldi, die Arie erklang außer in seinem Siroe auch in der 1730 in Prag und Wien gespielten Oper Argippo. Laut Textanalyse wurde sie nicht aus Argippo, sondern eher aus einer der Siroe-Vertonungen in Umstatts Oratorium übernommen (der Text wurde natürlich bearbeitet, doch die im B-Teil vorkommende Wendung „,anima fedele“ deutet auf Metastasios ursprüngliche Version hin). ${ }^{36}$

32 Libretto Cz-Bm B 325, př. 5. Das Libretto verzeichnet z. B. DOKOUPIL, Vladislav. Soupis brněnských tiskư. Staré tisky do roku 1800, Brno: Státní vědecká knihovna, 1978, S. 210.

Libretto Prag 1744: CZ-OLu 33.498. KAMPER, Otakar. Hudebni Praha v 18. věku. Praha, 1936, S. 252, erwähnt ein weiteres, in der Prager Nationalbibliothek aufbewahrtes Exemplar (unter dem Namen Giuseppe Amstatt), wo das Libretto jedoch nicht aufgefunden werden konnte.

34 FUKAČ, Jiří. Křižovnický hudební inventár. Přispěvek k poznání křižovnické hudebni kultury a jejího mista v hudebním životě barokni Prahy. Diplomarbeit, Brno 1959, Bd. 2, S. 56v.

EITNER, Robert. Biographisch-Bibliographisches Quellen-Lexikon der Musiker und Musikgelehrten. Leipzig, 1900-1904, Bd. 10, S. 9-10 (,La Vittima d'amori osia La morte de Christe, Ms. P., italiensich und deutsch"). Die Quelle wird als verschollen geführt, siehe GLÖCKNER, Andreas. Die ältere Notenbibliothek der Thomasschule zu Leipzig. Verzeichniss eines weitgehend verschollenen Bestands. Hildesheim: Olms, 2011, S. 291. Für die Gewährung dieser Information gebührt mein herzlicher Dank Frau Chrisitne Funk-Kunath aus dem Bach-Archiv Leipzig.

36 Für die Möglichkeit, diese Problematik zu konsultieren, danke ich aufs Herzlichste Herrn Ondřej Macek. 
Es gelang auch, in der Partitur von Caldaras Oratorium Morte e sepoltura di Cristo aus der Berliner Staatsbibliothek, die ich bereits vor einiger Zeit mit der Brünner Aufführung des Werkes in Jahre 1730 in Verbindung brachte, eine weitere Arie zu identifizieren. ${ }^{37}$ In dieser Partitur wurde der Arie von Maria di Giacobbe Lasciami, eterno amante ein neuer Text, Schernito e disprezzato, unterlegt. Dieser Text konnte bisher in keinem der in Mähren aufgeführten musikdramatischen Werke gefunden werden, er wurde erst jetzt im Umstatts Libretto entdeckt, und zwar als Arie der Jungfrau Maria vor dem Ende der ersten Teils des Oratoriums. Da der Part der Jungfrau Maria bei Umstatt einer Altstimme anstelle von Caldaras Sopran zugedacht war, musste sie zwangsläufig in einer Transposition erklingen.

Umstatts beträchtliche Reputation auf dem Posten des fürstlichen Kapellmeisters belegt auch das Libretto des Marienoratoriums, dass im Jahre 1745 zum hundertsten Jubiläum des Sieges der Brünner über die schwedischen Truppen aufgeführt wurde und wo ,der Kunstreiche und Virtuose Hr. Joseph Umstat" genannt wird. Der Werktitel lautet Das Durch Treu, und Andacht gecrönte JahrHundert Als Selbstes Den 15. August-Monat, am Tag Mariä-Himmelfahrt anfangend, durch drey Täg Mariae Der Himmels Königin Zu Ehren In der Königlichen, und Jungfräulichen Stadt Brünn Feyerlich gehalten worden. ${ }^{38}$ Das unter dem Titel Oratorio della Coronatione B.V.M. im Mährischen Landesmuseum deponierte musikalische Material stammt aus der Sammlung der Brünner Augustiner. ${ }^{39}$ Anders als bei La vittima d'amore wurde hier keine fremde Musik vorgefunden.

\section{Die von Bischof Schrattenbach initiierten Oratorienaufführungen}

Der Hauptpropagator des italienischen Oratoriums war der Olmützer Bischof Wolfgang Hannibal Schrattenbach, was uns in Anbetracht seiner Lebensschicksale und Kulturinteressen keineswegs überrascht. In den Jahren 1714-1722 weilte er in Italien, zwei Jahre lang amtierte er als Vizekönig von Neapel (1719-1721). Nach seiner Umsiedelung nach Mähren (1722) umgab er sich mit italienischen Hofleuten und Künstlern, auf seinen Schlössern ließ er Opern spielen, in denen italienische Kastraten mitwirkten. Das erste auf seine Weisung hin aufgeführte Brünner Oratorium ist im Jahre 1723 verzeichnet.

Schrattenbach ließ die italienische Oratorien in Brünn regelmäsig in der Fastenzeit allwöchentlich aufführen, aus einigen Jahren sind fünf oder sogar sechs

37 D-B Mus. Ms. 2720. Vgl. SPÁČILOVÁ, Jana. Nové poznatky k hudbě na dvoře olomouckého biskupa Schrattenbacha (zitiert in der Anm.). Nach der Kopistenschrift geurteilt, stammt die Partitur ursprünglich aus Salzburg.

38 Bibliothek der Brünner Augustiner, in CZ-Bu A-0000.104, přív.20. Digital-Kopie zugänglich auf www.manuscriptorium.com.

39 Stimmen CZ-Bm A 20.194. Die Musikalie ist undatiert, die Namen der Kopisten auf den einzelnen Stimmen sprechen für ihre Entstehung in den späten 50er Jahren des 18. Jahrhunderts. Siehe SPÁČILOVÁ, Jana. K provozování oratorií v Brně v 1. polovině 18. století. Opus musicum, 2013, 45, Nr. 6, S. 6-16. 
Titel bekannt. ${ }^{40}$ Der Aufführungsort war höchstwahrscheinlich der Schrattenbach-Palais in der Krapfengasse, das 1725 vom Bischof gekauft und von Moritz Grimm umgebaut wurde. Am Ende der 20er Jahre beteiligten sich an den Oratorienaufführungen aktiv Sänger aus dem Piaristenseminar in Kremsier, wo sich der Bischof einige Konviktoren zu den Zwecken ihres späteren Einsatzes in seiner Hofkapelle hielt. ${ }^{41}$ In den auf diese Fundation sich beziehenden Dokumenten wird die Mitwirkung der Sängerknaben in den bischöflichen Palästen sogar ausdrücklich erwähnt. ${ }^{42}$

Während der Anfangsphase um die Wende der 20er und 30er Jahre war das Repertoire vornehmlich auf Komponisten aus dem Umkreis des kaiserlichen Hofes in Wien orientiert. Eine führende Stelle nimmt dabei Antonio Caldara, dessen kompositorisches Können der Kardinal Schrattenbach bereits in Rom kennengelernt hatte, ein (1730 La caduta di Gerico, 1730 Morte e sepoltura di Christo, 1731 La passione di Giesu Cristo Signor nostro). Es folgen Johann Joseph Fux (1729 La deposizione dalla Croce, 1731 Cristo nell'orto) und Georg Reutter der Jüngere (1730 Bersabea, ovvero Il pentimento di David). Die Werke wurden relativ bald nach ihrer Entstehung in Brünn aufgeführt, ein nur einjähriger Abstand von ihrer Premiere in der kaiserlichen Hofkapelle ist keine Ausnahme. Die erhaltenen Libretti zeigen nur minimale Abweichungen von den Wiener Originalen. Größere Veränderungen lassen sich nur im Oratorium Bersabea, ovvero Il pentimento di David feststellen (Premiere Wien 1729). Es handelte sich wahrscheinlich um einen Autoreneingriff des Librettisten des Werkes, Giovanni Battista Catena, der kurz vor der Brünner Aufführung des Oratoriums in Schrattenbachs Dienste als dessen Sekretär getreten war.

Aus dem Jahre 1725 stammen zwei Oratorien von Antonio Caldara (Il rè del dolore in Giesù Cristo Signor nostro coronato di spine) und Giuseppe Porsile (Il sacrificio di Gefte), bei denen sich einige Unterschiede gegenüber dem sonstigen Schrattenbach-Repertoire vermerken lassen. Auf den Textbüchern wird kein Auftraggeber genannt, die Titelblätter geben ein genaues Datum an und die Texte

$40 \quad$ In seiner Korrespondenz spricht Bischof mehrmals von seinen Oratorien-Produktionen. Die neu entdeckte Briefe Schrattenbachs an seinem Bruder Sigmund, Bischof zu Laibach, sind derzeit intensiv erforscht.

41 Aus dem Jahre 1728 ist ein Bericht über den Aufenthalt der vom Regenten Jan Kopecký begleiteten Sängerknaben überliefert: „,P. David a S. Joanne qua Regens Seminarii pro oratoriis Italis iterum expectitus Brunam cum duobus discantistibus John et Weiss et Altista Walter ab ipso Eminentissimo, mansitus per totam quadragesimam " (Continuatio Annalium Domus Cremsiriensis ab Anno 1725, Národní archiv Praha [Nationalarchiv Prag], Abt. 1, Fond ŘPi - Piaristé (40), č. kn. 325, fol. 3r.). Der Diskantist Anton John (*1713) wirkte später am Schrattenbachs Hof als Bassist, siehe weiter unten.

„,... in denen Operen und andern musicalischen Actibus, so in [Kremsierer] Schloss herinnen oder in Ihro Hochf. Em. Anderwertigen Palazzen vorgestellt werden". Decretum an den P. Rectorem, Kremsier 18. 9. 1728, cit. nach SEHNAL, Jiř́i. Musik in den Piaristenkollegien in Mähren im 17. und 18. Jahrhundert. In Piaristen und Schulwesen, Wissenschaft, Kunst in Mitteleuropa im 17.-19. Jahrhundert, S. 99-116, hier auf S. 109. Für den Hinweis auf diese Quelle danke ich herzlichst Herrn Prof. Jiří Sehnal. 
enthalten spezielle Zeichen, die auf ,arie aggiunte“ hinweisen. In Anbetracht dessen, dass zu dem Oratorium Il sacrificio di Gefte eine Partitur (allerdings ohne eingefügte Arien) in der Sammlung des Grafen Questenberg existiert, bleibt die Frage des Auftraggebers vorerst offen - es konnte sowohl Schrattenbach, als auch Questenberg gewesen sein.

Bei insgesamt vier der Schrattenbach-Oratorien konnte bisher die Autorschaft nicht zuverlässig bestimmt werden. Die Oratorien Cantata sacra, in cui si considera la deposizione dalla croce, dell'amorisissimo Redentor Nostro Gesù (1723) und Componimenti sacri da cantarsi nella sera del Venerdi Santo, ed in quella della Domenica di Pasqua di Resurrezione (1724) hängen eng miteinander zusammen - der Text des ersteren wurde als Parte seconda einer Kantate zum Karfreitag des darauffolgenden Jahres verwendet. Das Oratorium Il peccato di Adamo (1726) entstand, wie einem in der Musikgeschichtlichen Abteilung des Mährischen Landesmuseums aufbewahrten Fragment seines Notenmaterials zu entnehmen ist, wahrscheinlich als ein Pasticcio (siehe weiter unten). Das letzte anonyme Stück, La speranza consolata da S. Nicolo vescovo di Mira (1729) hängt thematisch mit Schrattenbachs Neapolitanischem Wirken zusammen, zu den Musik- und Textverfassern konnte jedoch nichts Näheres ermittelt werden.

$\mathrm{Zu}$ den direkt im Umkreis des bischöflichen Hofes entstandenen Kompositionen zählen drei Oratorien von Wenzel Matthias Guretzky, welcher in den Jahren 1731-1736 Schrattenbachs „compositore di camera“ gewesen war (1731 Giacobbe, 1734 S. Francesco di Paola, 1736 Gioas, re di Giuda). Das Libretto zum ersten von ihnen schrieb Schrattenbachs Sekretär Giovanni Battista Catena, es handelte sich also um ein Werk ausgesprochen einheimischer Provenienz. Das vierte Stück war Il giusto afflitto nella persona di Giobbe des bischöflichen Kapellmeisters Girolamo Pera aus Venedig (1738). Der Text von Claudio Pasquini wurde bereits zwei Jahre früher in Wien von Ignazio Conti vertont.

Einen beträchtlichen Teil des Repertoires bilden von anderweitigen Aufführungen her bekannte Oratorien italienischer Komponisten. Vier von ihnen hängen mit den Bindungen des Kardinals an Rom zusammen, die Premieren zweier Werke fielen direkt in die Zeit seines dortigen Aufenthaltes. Das erste Stück ist das Oratorio per la Santissima Annunziata von Antonio Caldara, das in Brünn ohne die Namensangabe seines Komponisten als La santissima annunciazione di Maria Vergine gespielt wurde (1729). Caldara hatte das Oratorium in Rom im Jahre 1713 komponiert, die Premiere erfolgte jedoch erst im März 1715 im Palais des Marquis Ruspoli auf der Via del Corso. Für dieses Jahr sind Schrattenbachs Besuche der Musikabende bei Ruspoli belegt. Eines der dort gespielten Oratorien (oder dessen Teil) hatte er sogar in einer Abschrift nach Salzburg geschickt, wie einem vom Bruder des Bischofs, dem Salzburger Domherrn Sigmund Felix im April 1715 geschriebenen Brief zu entnehmen ist (die Arien von Ruspoli wurden in Salzburg ,sehr applaudirt").$^{43}$ Caldaras Werk wurde für Brünn partiell bearbeitet - die ursprünglich drei Teile wurden in zwei zusammengefasst und es entfielen 
die Chöre. ${ }^{44}$ Das Stück Sant'Alessio (1729) führte man in Brünn anonym auf, es handelte sich wahrscheinlich um das gleichnamige Oratorium von Girolamo Chiti (ca. 1678-1759), das 1722 im Seminarium Romanum gegeben wurde. Auch dieses Werk wurde zu den Zwecken der Brünner Aufführung einer Bearbeitung unterzogen. Sieben Arien wurden gestrichen, zwei mit einem neuen Text versehen, eine Arie in ein Rezitativ verwandelt. ${ }^{45}$

Zwei weitere Oratorien wurden 1725 in Rom uraufgeführt, zu einer Zeit also, wo Schrattenbach bereits in Mähren war. Santo Ermengildo von Domenico Sarrò, gespielt im Seminarium Romanum, war das erste für Rom geschriebene Oratorium dieses Komponisten. Giovanni Battista Costanzi (1704-1778), seit 1721 als Musiker beim Kardinal Ottoboni tätig, verfasste sein Oratorium Santa Cecilia für die Archiconfraternità del Santissimo Crocifisso. Bei diesen 1727 bzw. 1730 in Mähren aufgeführten Werken wurde bisher kein Vergleich mit der Originalversion vorgenommen.

Die nächsten drei Oratorien gehören zu den ältesten Stücken des Schrattenbach-Repertoires, sie stammen aus dem ersten Jahrzehnt des 18. Jahrhunderts. Santa Catterina (1731) von Pietro Sandoni wurde angeblich 1706 unter dem Titel Santa Caterina V. e M. in Bologna aufgeführt. ${ }^{46}$ Das Libretto von der Premiere konnte bisher nicht identifiziert werden, ebenso rätselhaft ist, wie das Werk nach Mähren gelangte.

Bei den weiteren beiden Oratorien ist ihr Weg schon klarer. Hinter der Aufführung von L'ultima persecuzione di Saule contro Davidde (1731) steht offenbar sein Verfasser Francesco Peli persönlich. Die Hypothese seines mährischen Aufenthaltes kann durch zwei Tatsachen bestärkt werden: im Sommer 1731 ist Pelis Oper Coronide, deren sonstige Aufführungsgeschichte unbekannt ist, in Kremsier über die Bühne gegangen, im gleichen Jahr wurde von den Vorstehern der dortigen St. Moritz-Kirche eine Sammlung italienischer Musikalien, unter denen Pelis Kompositionen einen bedeutenden Rang einnehmen, gekauft. Diese Sammlung ist in Kremsier bis heute erhalten geblieben. ${ }^{47}$

Die Premiere des Oratoriums Il trionfo della croce von Giacomo Cesare Predieri ereignete sich zwar im Jahre 1702 in Bologna, nach Brünn kam das Werk jedoch über Salzburg. Die Salzburger Aufführung belegt ein bei Johann Josef Mayr gedrucktes undatiertes Libretto Il trionfo della Santa Croce, sowie eine vom dortigen Schreiber Johann Jacob Rott kopierte Partitur, über die noch später die Rede

pobočka Olomouc [Landesarchiv Opava, Zweigstelle Olomouc], Fond AO, Schrattenbachs Korespondenz, Fasc. XII.

Zum Vergleich diente die Autographpartitur in A-Wgm, sign. III 16160, Rud. Ms 109. Oratorio Per la SS:ma Annunziata à 5 voci Con Strom:ti Di Ant:o Caldara.

Als Vergleichsmaterial diente das Libretto I-Mb Racc. dram. 5653/2.

Libretto B-Bc Lo.7512, zitiert nach: GASPARI, Gaetano. Catalogo della Biblioteca del Liceo Musicale di Bologna. Bd 5, Libretti d'opera in musica, ed. Ugo Sesini. Bologna, 1943, S. 487.

SPÁČILOVÁ, Jana. Chrámová hudba v Kroměříži v roce 1731. Olomoucký biskup Schrattenbach a hudba vrcholného baroka [3]. Opus musicum, 2005, Nr. 3, S. 39-45. 
sein wird. Die enge Beziehung des Bischofs Schrattenbach zu Salzburg bestand bereits seit jener Zeit, wo er dort Domherr und später dann Domdechant gewesen war (1682-1711). In den Jahren 1703-1727 wirkte in Salzburg auch sein Bruder Sigmund Felix, der spätere Bischof von Laibach, mit dem er laut erhaltener Korrespondenz sowohl Musikalien, als auch Sänger auszutauschen pflegte.

Die übrigen drei Oratorien erklangen hingegen in Mähren relativ bald nach ihrer Premiere. Bei Porporas Il martirio di S. Giovanni Nepomuceno (1732) ist sogar nicht einmal eine frühere Aufführung nachgewiesen, das vermutliche Entstehungsdatum (Venedig 1730) geht nur aus indirekten Belegen hervor. Als weiterer Premierenort kann jedoch Mailand in Erwägung gezogen werden. In dem Jahre 1726 (Imprimatur des Librettos datiert 7. 6. 1726) wurde dort ein gleichnamiges Oratorium, Il martirio di S. Giovanni Nepomuceno, dessen Text mit dem Brünner Libretto und der in Berlin aufbewahrten Partitur wörtlich übereinstimmt. ${ }^{48}$ Der Komponist wird in diesem Druck nicht vermerkt, doch Porpora hatte zu dieser Zeit zweifellos Beziehungen zu Mailand, wo zur Jahreswende 1725/1726 seine Oper Siface aufgeführt wurde. Während der Karnevalszeit 1726 bereitete er persönlich die Aufführung ebendieses Werkes im angesehenen Venezianischen Theater S. Giovanni Crisostomo vor, worüber Johann Joachim Quantz in seinem Lebenslauf berichtet. Die Oper wurde in Mailand und Venedig parallel gespielt, wobei Porpora an der Mailänder Version wahrscheinlich nur teilweise partizipierte. Im Januar 1729 wurde Siface im Theater des Grafen Sporck in Prag gegeben. ${ }^{49}$ Die Beziehung zwischen den beiden Werken wird noch dadurch bestärkt, dass diese Oper bis auf geringfügige Unterschiede in der Instrumentierung das gleiche Vorspiel hat, wie das Oratorium Il martirio di S. Giovanni Nepoтисеno. Zu Porporas Oratorium gibt es drei Partiturexemplare, von denen sich eines auf die Brünner Aufführung von 1732 bezieht, das zweite aus der Sammlung des Grafen Quenstenberg stammt und das dritte italienischer Provenienz ist. ${ }^{50}$ Da diese Partituren interessante wechselseitige Zusammenhänge vor allem im Hinblick auf die einzelnen Text- und Instrumentierungsvarianten aufweisen, soll das Werk zum Gegenstand weiterer Untersuchungen werden.

Ein interessanter, das italienische, mährische und Prager Repertoire verbindender Titel ist $S$. Elena al Calvario von Leonardo Leo (1733). Leo schrieb das Oratorium im Jahre 1732 auf Bestellung des als Vizekönig von Neapel amtierenden Grafen Harrach.$^{51}$ Die Brünner Aufführung ist die erste unter den folgenden Wiedergaben, im gleichen Jahr wurde es noch in Modena gespielt. Ein Jahr später (1734) wurde das Werk in einer lateinischen Übersetzung und mit zwei Einlage-

48 Libretto I-Mb XMX.VI.15.

49 SPÁČILOVÁ, Jana. Niccolò Porpora a jeho opera Siface: vítězství neapolského stylu v českých zemích, Opus musicum, 2013, 45, Nr.3, S. 36-42.

50 D-B Mus.Ms. 17781 (italienischer Kopist, mit Einlagearien für Aufführung in Brünn 1732); A-Wn Mus.Hs.19159 Mus (Venezianischer Kopist); A-Wn SA.68.C.9 Mus 36 (Wiener Kopist, aus der Sammlung des Grafen Questenberg).

51 Handschriftliches Libretto A-Wn Cod. 12.805, auch das Titelblatt von Kiesewetters Abschrift in A-Wn. 
arien bei den Jesuiten in Prag gegeben. ${ }^{52}$ Der Text des Brünner Librettos weicht im Unterschied zu Prag nicht von Metastasios Urfassung ab.

Auch im Falle des letzten Oratoriums, La passione di Giesu Christo von Giuseppe Venturelli, konnte das Material zu der bei Eitner mit 1735 datierten Premiere bisher nicht aufgefunden werden. ${ }^{53}$ Bekannt ist lediglich das Libretto von einer 1738 - also ein Jahr später, als in Brünn - stattgefundenen Aufführung in Modena. Sein Text stimmt mit dem Brünner Libretto überein. ${ }^{54}$

\section{Unbekanne Brünner Oratorien}

Der interessanteste und zugleich strittigste Teil des Brünner Oratorien-Repertoires ist eine Gruppe von zehn Werken aus den 30er Jahren, die von anderweitigen Aufführungen her nicht bekannt sind und als deren Verfasser mehr oder weniger renommierte italienische Komponisten figurieren. In Anbetracht von Schrattenbachs Kontakten mit Italien ließe sich annehmen, dass diese Oratorien direkt im Auftrag des Bischofs komponiert worden sind. Diese Hypothese konnte jedoch leider weder durch die bischöfliche Korrespondenz, noch anhand von anderem Archivmaterial belegt werden.

Das älteste Stück ist Il mondo trionfante nella concezione di Maria sempre Vergine von Niccolò Logroscino (1730), es handelte sich um das überhaupt erste bekannte Werk dieses Komponisten, der sich später im Genre der komischen Oper hervortat. Das Textbuch schrieb laut Angaben auf dem Libretto der „Dottor Filippo Itto Napolitano“, eine weitere Vertonung des Textes ist nicht bekannt.

Das in der chronologischen Reihenfolge nächste Werk ist Il trionfo della virtù in S. Nicolò di Bari von Leonardo Leo (1732). Das Sujet aus dem Leben des Patrons des Königsreiches Neapel erinnert an Schrattenbachs einstige Vizekönigszeit. Als Librettist nennt der Brünner Druck ähnlich wie auch in anderen Fällen, einen „Pastore Arcade“. Nach dem Text-Incipit wurde das Libretto als S. Nicola di Bari von Silvio Stampiglia, das mit Musik von Giovanni Bononcini 1693 erstmalig in Rom erklang und später unter anderem 1699 in Wien weiderholt wurde, identifiziert.

Im gleichen Jahr spielte man in Brünn das erste der zwei Oratorien von Leonardo Vinci, La santissima annunziazione di Maria sempre Vergine (1732). Der anonyme Librettist wurde lediglich als „Pastore Arcade“ bezeichnet, eine andere Vertonung oder Aufführung des Werkes ist nicht bekannt. Die Thematik des zweiten Oratoriums von Vinci, La donna forte (1737), war dem 4. Kapitel aus dem Buch der Richter entnommen. Das Libretto wurde von Cesare Benassai verfasst, vor Vinci vertonte den Text 1719 Pietro Lombardi in Modena. Benassai

\footnotetext{
52 Näheres dazu im Beitrag von Michaela Freemannová.

53 EITNER, Robert. Quellenlexikon (zit. in Anm.), Bd. 10, S. 52.

54 Als Vergleichsmaterial diente das Libretto I-Vgc ROL.0645.14.
} 
wird nur bei diesem einzigen Libretto als Autor angegeben, es ist über ihn nichts Näheres bekannt.

Die Autoren der nächsten beiden Werke fallen nicht in den Kreis der Neapolitanischen Komponisten, der erste von ihnen stammte aus Venedig, der zweite aus Florenz. Die Autorschaft des Oratoriums Il candor vendicato di Nostra Signora (1736) gebührt Giovanni Porta, das Brünner Textbuch trägt die Venezianische Version seines Namens, nämlich „Zanetto“. Der Librettist wird auf dem Druck als „Dottore Antonio Cassetti“ bezeichnet. Die Musikhistoriographie vermerkt diesen Namen nicht, sie kennt lediglich einen möglichen Verwandten (?), Giacomo Cassetti, welcher in den Jahren 1708-1717 sieben vorwiegend lateinische Oratorientexte, unter anderem für Antonio Vivaldi, schrieb.

Als Komponist des Oratoriums La conversione si S. Pellegrino Laziosi (1737), wurde der als „Redi Fiorentino“ angegebene, im Zeitraum 1715-1755 in Florenz tätige Giovanni Nicola Ranieri Redi bestimmt. Die Thematik des Werkes zeigt wieder einen Zusammenhang mit Schrattenbach - Pellegrin Laziosi war ein Heiliger aus dem Orden der Serviten, dem eine der Kapellen in der römischen Titularkirche des Kardinals, San Marcello al Corso, geweiht war. Der Librettist ist unbekannt, ein Oratorium mit dem gleichen Text wurde 1729 in Bologna von Luca Antonio Predieri komponiert.

Der Komponist des nächsten Werkes, San Vicenzo Fererio (1737), Giuseppe Bonno, wird auf dem Brünner Libretto mit dem Attribut „di Napoli“ versehen, wenngleich er aus Wien stammte und nach zehnjähriger musikalischer Ausbildung in Neapel auch dorthin zurückgekehrt war. In Anbetracht dessen, dass sein Neapolitaner Aufenthalt knapp der Brünner Aufführung des Oratoriums vorausging, ist dieser Irrtum wohl begreiflich. Er konnte allerdings auch vorsätzlich und zwecks Prestigeerhöhung in Brünn als ein Neapolitanischer Komponist inseriert werden. Der Anonyme Librettist verbirgt sich, ebenso, wie in zahlreichen anderen Fällen, wieder unter der Chiffre „Pastore Arcade“. Ein gleichnamiges Oratorium wurde 1740 in Perugia gespielt, da das Libretto jedoch keine Angaben über den Komponisten macht, lässt sich nicht feststellen, ob es sich um eine Reprise des Brünner Oratoriums oder um eine Neuvertonung handelte.

Die meisten Zweifel erwecken zwei Oratorien von Francesco Araja, Daniello (1737) und David umiliato (1738). Dieser Komponist widmete sich dem Oratorienschaffen nicht allzu sehr, es ist von ihm nur noch ein einziges weiteres Werk dieser Gattung bekannt. Die beiden Libretti schrieb im Jahre 1731 Apostolo Zeno, für Brünn wurden die Texte jedoch in einem mit den anderen untersuchten Libretti kaum vergleichbaren Maße abgewandelt. Bei Daniello sind aus der Gesamtzahl von 17 Musiknummern nur 4 Arien unverändert geblieben. Keine der Musiknummern wurde gestrichen, die Texte werden verschiedenartig paraphrasiert. Auch bei dem zweiten Araja-Oratorium als dem folgenden Jahr kommen ähnliche Änderungen vor, von den insgesamt 14 Nummern werden nur 9 von Zeno übernommen. Eine Arie bringt eine Paraphrase des Zeno-Textes, weitere Arien sind neu.

Die Arien wurden bestimmt wenigstens teilweise durch Entlehnungen ersetzt, wie die Arie von Amyti Che gran pena traffige il suo core aus Daniello, die bis 
auf geringfügige Abwandlungen mit Osiras Arie Che gran penna traffige il mio core aus Antonio Costantinis 1733 von der Mingotti-Gesellschaft in Brünn aufgeführtem pasticcio Agrippo identisch ist, zeigt. Der Ursprung dieser Arie geht auf Hasses Oper Tigrane zurück, später erklang sie dann in einigen Reprisen von seinem Artaserse. Außerdem kommt sie in einem zwischen den Jahren 1730 und 1733 für die Operngesellschaft von Giovanni Maria Peruzzi verfassten Pasticcio, in dem Arien aus Vivaldis Agrippo identifiziert wurden und dessen Partituren sich in Darmstadt (die ganze Oper) und Regensburg (nur Arien) befinden..$^{55}$

Das letzte anderweitig unbekannte Brünner Oratorium ist La divina pietà trionfante nell'imaculata concezione di Maria Vergine (1738) von Niccolò Porpora. Der Librettist wird nicht angegeben, ein gleich betiteltes Oratorium schrieb 1730 in Bologna Michele Fini.

\section{Musikalisches Material zu den Brünner Oratorien}

Die Frage nach der Entstehung der sonst unbekannten Brünner Oratorien kann vielleicht teilweise das bisher identifizierte Musikmaterial, das die Art und Weise des Umgangs mit musikdramatischen Werken in der hiesigen Umgebung dokumentiert, beantworten. Der erste musikalische Beleg zu den Brünner Oratorien wurde in der Musiksammlung vom Heiligenberg bei Olmütz, die heute in der Musikabteilung des Mährischen Landesmuseum aufbewahrt wird, gefunden. Es handelt sich um ein Fragment des Oratoriums Il peccato di Adamo aus dem Jahre 1726. Zur Herstellung von Umschlägen zweier Messen von Fux und Caldara wurden mehrere Seiten mit Violin- und Gesangparts verwendet, aus denen sich ein Accompagnato-Rezitativ und zwei Arien rekonstruieren lassen. ${ }^{56}$

Eine dieser Arien, Al tuo voler sovrano, entstand durch Neutextierung und Bearbeitung der Arie M'insegna amor l'inganno aus der Oper Astarto von Giovanni Bononcini. Diese Oper wurde in Rom 1715 (das heißt während des dortigen Aufenthaltes von Schrattenbach) uraufgeführt und 1730 dann in Kremsier gegeben (die im Oratorium verwendete Arie erklang bei dieser Reprise allerdings nicht). Aus alledem lässt sich darauf schließen, das das anonyme Oratorium als ein mit neuem Text unterlegtes Pasticcio entstand, was in unseren Ländern kein Ausnahmeverfahren war - ähnlich wurde bei den Kreuzherren in Prag ein Oratorium mit Musik von Georg Friedrich Händel (Fides, Spes, Charitas peccatorem ex contemplatione passionis ad paenitentiam invitantes, 1725, Text von Karl Kořínek),

55 SPÁČILOVÁ, Jana. Brněnská opera Argippo z roku 1733 ve světle nových výzkumů. Opus musicum, 2013, 45, Nr. 2, S. 6-21. Vgl. auch: STROHM, Reinhard. Argippo in „Germania“. Studi Vivaldiani, 2008, 8, S. 111-127; PEGAH, Rashid-S. Ein Argippo-Pasticcio. Studi Vivaldiani, 2011, 11, S. 63-76.

56 CZ-Bm A 20763 (Fux: Missa), A 20648 (Caldara: Missa Sancti Jacobi Minori Apostoli). SPÁČILOVÁ, Jana. Nově identifikované hudební materiály k oratoriu Il peccato di Adamo (Brno 1726). In Hudba v Olomouci a na střední Moravě I. In memoriam Vladimír Hudec. Olomouc, 2007, S. 253-266. 
oder im Zisterzienserkloster Osek das lateinische Karnevalspiel Facetum musicum (vor 1738, mit Arien von Georg Friedrich Händel, Antonio Lotti und Antonio Vivaldi) geschaffen..$^{57}$

Drei bereits identifizierte komplette Partituren von Brünner Oratorien werden heute in der Berliner Staatsbibliothek aufbewahrt. ${ }^{58}$ Die ersten beiden - Predieris Il trionfo della croce und Caldaras Morte e sepoltura di Christo - kamen nach Brünn aus Salzburg, da sie vom dortigen Kopisten Johann Jacob Rott abgeschrieben worden waren. In allen drei Partituren befindet sich eine größere Anzahl von Einlagenarien. In Predieris Oratorium sind das Vorspiel und fünf neu eingefügte Arien von einer anderen Hand geschrieben, außerdem wurden an einigen Stellen auch die Rezitative umgearbeitet und kürzere Abschnitte im ursprünglichen Notentext abgeändert. Da keine andere Partitur als eben diese bekannt ist, war es nicht möglich, zu ermitteln, ob hier fremde Musik vorkommt. Das Ergebnis der Nachforschungen im RISM-Incipitkatalog war negativ, neue Musik lässt sich allerdings bei der mit einem Violoncello-Solo versehenen Arie Cerco nel mio gioire, wo sich der Brünner Text von dem Salzburger Libretto teilweise in der Silbenzahl unterscheidet, vermuten. ${ }^{59}$

In der Caldara-Partitur Morte e sepoltura di Christo kommt neben kleinerer Veränderungen eine eingefügte Arie an der Stelle von Nicodemo's Gioia la cruda morte vor. Diese Einlage konnte als die Tenorarie des Orcano Son pellegrino errante aus Porporas Oper Siface, von der bereits im Zusammenhang mit der Entstehung des Oratoriums Il martirio di S. Giovanni Nepomuceno des gleichen Komponisten die Rede war, identifiziert werden. ${ }^{60}$ Die Korrekturen und die Verteilung der Balken lassen vermuten, dass der Text der Arie nachträglich unterlegt wurde, der erste Takt ist sogar überklebt. Im A-Teil kam es zur Streichung zweier schwieriger Koloraturpassagen. Bei einer weiteren Arie wurde direkt in Rotts

57 SPÁČILOVÁ, Jana. Händel v barokní Praze. Dosud neznámé doklady provozování Händelovy hudby v chrámu pražských křižovníků s červenou hvězdou v první polovině 18 . století. Musicologica Brunensia. SPFFBU, H 38-40 (2003-2005). Brno 2006, S. 237-244; MACEK, Ondřej - SPÁČILOVÁ, Jana. Nová zjištění k latinské karnevalové opeře Facetum Musicum / Musicalisches Kurtzweil-Spiel (Osek 1738). Hudební věda, 2011, 48, Nr. 2-3, S. $143-160$.

58 Näheres zur Identifizierung der Partituren der Brünner Oratorien siehe SPÁČILOVÁ, Jana. Die Rezeption (zitiert in Anm.). Hier ist auch die entsprechende Bilddokumentation zu finden.

59 Als Vergleichsmaterial diente das Libretto Il Trionfo della Santa Croce, I-Mb Racc. dram. 5626. Die Ähnlichkeit mit dem Brünner Libretto ist für jene Zeit beträchtlich, die Texte der Libretti entsprechen einander (bis auf zwei Ausnahmen) auch in der Akzentsetzung, der Interpunktion und der Majuskelschreibung.

60 Aria Son pellegrino errante kommt in der Venezianischen und Prager Fassung der Oper vor, die Mailänder Version lässt diese Arie vermissen. Ausserdem ist die Arie in mehreren selbstständigen Abschriften überliefert: B-Bc 15179/1 (RISM ID no. 701001542, für Sopran), I-Vlevi CF.B.43 (RISM ID no. 850011601, für Tenor). In Venedig war ihr Interpret Giovanni Paita, in Prag Matteo Lucchini. 
Partitur ein neuer Text Schernito, e disprezzato unterlegt, die Arie wurde (wie bereits erwähnt) 1741 in Umstatts Oratorium La vittima d'amore verwendet.

In Partitur von Porporas Il martirio di S. Giovanni Nepomuceno sind insgesamt vier Arien und ein Duett von anderer Hand geschrieben, es handelt sich meistens um bloße Transpositionen. Wir finden nur eine einzige Anleihe, und zwar Come all'Olimpo in cima, bestimmt für die Tenorpartie des Consigliere. Die Arie ist (wohl in Übereinstimmung mit der Vorlage) im Sopran- statt im Tenorschlüssel

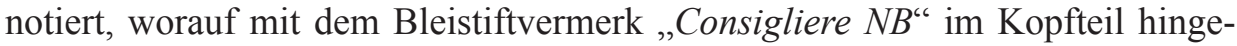
wiesen wird. Die Herkunft der Arie konnte nicht eruiert werden.

Diese Partitur ist auch eine bedeutende Quelle im Hinblick auf die Erforschung der Migration des weltlichen und geistlichen Repertoires auf Schrattenbachs Hof. Bei zwei Arien sind besondere Zettel eingeklebt. Vor der Arie L'amica speme klebt ein Zettel mit dem Vermerk „Jon Manete | Atto Terzo | Qual ripercossa | Selce Sfavilla etc. "Vor der Arie Pellegrin che in notte oscura befindet sich der Rest des Zettels, wo man ,,[...] te | dolente | etc. “ lesen kann. Diese Zettel weisen auf die Verwendung beider Arien in einem anderen Werk hin, wobei dieses ohne Zweifel die 1735, das heißt drei Jahre nach der Aufführung von Porporas Il Martirio di S. Giovanni Nepomuceno, am Hofe des Kardinals gespielte Oper Nitocri war. Jenes „Jon“ vor der Rollenbezeichnung bezieht sich außerdem höchst wahrscheinlich auf dem Hofsänger Anton John. Dieser war zwar Bassist, kann jedoch die betreffende Arie in einer Transposition gesungen haben, wofür auch die zahlreichen Umarbeitungen in der Partitur sprechen würden. ${ }^{61}$

In sämtlichen untersuchten Partituren konnte eine gewisse Anzahl von Entlehnungen vorgefunden werden, weitere Fälle wurden aufgrund von LibrettiAnalysen ermittelt. Es sollte darauf hingewiesen werden, dass die angeführten Beispiele nur Stichproben sind, die vom gegenwärtigen Stand der Evidenz der musikdramatischen Werke des 18. Jahrhunderts ausgehen. Vorläufig haben wir eine Datenbank der in Mähren aufgeführten Arien zur Verfügung, nach ihrer Erweiterung (mindestens auf das mitteleuropäische Territorium) würden sich gewiss weitere, bis jetzt nicht bestimmte Texte identifizieren lassen. ${ }^{62}$ Die italienische Opern- und Oratorienproduktion ist zu jener Zeit zwar riesig gewesen, doch es gab, wie die Beispiele Gelido in ogni vena oder Che gran pena traffige il mio core zeigen, besonders beliebte, durch ganz Europa wandernde Arien und es ist sicher interessant, dass sie auch in den Brünner Oratorien nachgewiesen werden konnten.

61 Von Anton John war die Rede bereits im Zusammenhang mit dem Einsatz der Sänger aus dem Piaristenseminar von Kremsier bei den Brünner Oratorienproduktionen des Jahres 1728. Näheres zu diesem Sänger und zu den weiteren Interpreten des Schrattenbachschen Hofes siehe SPÁČILOVÁ, Jana. Nové poznatky (zitiert in Anm.).

Ein Arbeitkatalog der in Mähren aufgeführten italienischen Opernarien wurde im Rahmen des Projekts „Catalogue of the Italian opera Libretti in Central Europe in the 1st Half of the 18th Century, I: Moravia“ (Grantagentur der Tschechischen Republik, Reg. Nr. P409/12/ P940, Hauptlöserin Jana Spáčilová, im Rahmen der Association for Central European Cultural Studies Prag), erarbeitet. 
Im Hinblick auf unser Thema ist ausschlaggebend, dass es keine Rolle spielte, ob eine Arie einem geistlichen oder einem weltlichen musikdramatischen Werk entliehen wurde. In den Brünner Oratorien wurden bisher vornehmlich Opernarien identifiziert, doch wie das Beispiel Il martirio di S. Giovanni Nepomuceno deutlich macht, war auch das umgekehrte Vorgehen, wo Arien aus einem Oratorium in eine Oper aufgenommen wurden, keine Seltenheit. Die ermittelten Tatsachen stellen uns jedoch vor die Notwendigkeit, einen etwas unangenehmen Gedanken zuzulassen. Neben der Hypothese, dass die anderweitig unbekannten italienischen Oratorien direkt auf Bestellung des Bischofs Schrattenbach als Ergebnis seiner italienischen Kontakte geschrieben wurden, muss man nun eine andere, nicht weniger wahrscheinliche Möglichkeit in Erwägung ziehen: nämlich dass diese Oratorien als Pasticci aus neu textierten Opernarien entstanden sind und dass die als ihre Autoren angegebenen Komponisten davon, dass sie diese Werke gleichfalls „komponiert“ haben, nicht die leiseste Ahnung hatten.

\section{Beilage}

\section{Beilage 1: Die bisher unbekannten Werke von italienischen Komponisten} (die Namen der Komponisten und Librettisten werden entsprechend dem jeweiligen Brünner Libretto angeführt, die bereits identifizierten Autoren stehen in Klammern)

Niccolò Logroscino Napolitano / Dottor Filippo Itto Napolitano: Il mondo trionfante nella concezione di Maria sempre Vergine (1730)

Rolen: Grazia - Innocenza - Speranza - Invidia

Textincipit: „Dalla Magion suprema“

Leonardo Leo Napolitano / Pastore Arcade [Silvio Stampiglia]: Il trionfo della virtù in S. Nicolò di Bari (1732)

Rolen: Epifanio Padre - Giovanna Madre di - S. Nicolò - Clizio

Textincipit: „Figlio, la via del Cielo“

Leonardo Vinci Napolitano / Pastore Arcade: La santissima annunziazione di Maria sempre Vergine (1732)

Rolen: Onnipotenza - Giustizia - Pensiero di Meditazione - Tempo

Textincipit: „E come, e qual consiglio“

Zanetto Porta / Dott. Antonio Cassetti: Il candor vendicato di Nostra Signora (1736)

Rolen: Maria Vergine - S. Giuseppe - Angelo - Mondo - Demonio - Coro di Mondani - Coro di Mortali

Textincipit: „Qual densa nube di tristezza, e duolo“ 
Leonardo Vinci / Cesare Benassai: La donna forte (1737)

Rolen: Debora Profetessa - Iael Donna Ebbrea - Barac Capitano del Popolo Ebreo - Giabino Re de Cananei - Sisara suo Capitano Generale - Coro d'Israeliti Textincipit: „Ti sento o sommo Iddio“"

Redi Fiorentino [Giovanni Nicola Ranieri Redi] / Pastore Arcade: La conversione di S. Pellegrino Laziosi (1737)

Rolen: S. Pellegrino - Maria Vergine - S. Filippo Benizzi - Angelo

Textincipit: „Or che da queste mura“

Giuseppe Bonno di Napoli / Pastore Arcade: San Vicenzo Fererio (1737)

Rolen: Enrico - Mitilde - Daliso Schiavo - San Vicenzo - Emilio Figlio pargoletto - Coro

Textincipit: „Questo è l'amore, e questa“

[Francesco] Araja Napolitano / Apostolo Zeno: Daniello (1737)

[Francesco] Araia Napolitano / Apostolo Zeno: David umiliato (1738)

Nicola Porpora / Pastore Arcade: La divina pietà trionfante nell'imaculata concezione di Maria Vergine (1738)

Rolen: Pietà Divina - Gabrielle - Adamo - Lucifero

Textincipit: „Dovunque il guardo io volgo, o in Cielo o in Terra“

\section{Beilage 2: Liste der identifizierten Entlehnungen}

OPER - ORATORIUM

- M'insegna amor l'inganno (Bononcini: Astarto, Rom 1715, Kremsier 1730) $\rightarrow \mathrm{Al}$ tuo voler sovrano (Anonym: Il peccato di Adamo, Brünn 1726)

- Son pellegrino errante (Porpora: Siface, Venezia 1726, Prag 1729) $\rightarrow$ Gioja la cruda morte (Caldara: Morte e sepoltura di Christo, Brünn 1730)

- Unbekanntes Werk (Sopranarie) $\rightarrow$ Come all'Olimpo in cima (Porpora: Il martirio di S. Giovanni Nepomuceno, Brünn 1732)

- Gelido in ogni vena (nur Text, Metastasio: Siroe 1726, Vivaldi: Argippo, Prag/Wien 1730) $\rightarrow$ Gelido in ogni vena (Umstatt: La vittima d'amore, Brünn 1741)

- Che gran pena traffigge il mio core (Text, villeicht auch mit Musik. Hasse: Tigrane 1729, Costantini: Argippo, Brünn 1733) $\rightarrow$ Che gran pena traffigge il suo core (Araja: Daniello, Brünn 1737)

\section{ORATORIUM - OPER}

- L'amica speme (Porpora: Il martirio di S. Giovanni Nepomuceno, Brünn $1732) \rightarrow$ Qual ripercossa (Nitocri, Wischau 1735) 
- Pellegrin, che in notte oscura (Porpora: Il martirio di S. Giovanni Nepomuceno, Brünn 1732) $\rightarrow$ Morirà, forse innocente (Nitocri, Wischau 1735)

\section{ORATORIUM - ORATORIUM}

- Lasciami, eterno amante (Caldara: Morte e sepoltura, Wien 1724, Brünn $1730) \rightarrow$ Schernito, a disprezzato (Umstatt: La vittima d'amore, Brünn 1741)

\section{Beilage 3: Verzeichnis der bisher bekannten, in der 1. Hälfte des 18. Jahr- hunderts in Mähren aufgeführten Oratorien}

WHS: Wolfgang Hannibal Schrattenbach, JAQ: Johann Adam Questenberg, JMTV: Johann Matthias Thurn-Valsassina, FAR: Franz Anton Rottal.

Sprache: it. - italienisch; dt. - deutsch; it./dt. - italienisch/deutsch zweiseitig; it.+dt.res. - italienisch mit deutschem Resümee; it., dt. - Sprachversionen in einzelnen Bände; lat. - lateinisch.

Die Bibliothekssigel nach www.rism.info, SOKA Přerov = Státní okresní archiv Přerov.

\begin{tabular}{|c|c|c|c|c|}
\hline Jahr & Titel & Ort / Auftraggeber & $\begin{array}{l}\text { Komponist / } \\
\text { Librettist }\end{array}$ & $\begin{array}{l}\text { Libretto (Sprache) } \\
\text { / Musik }\end{array}$ \\
\hline 1721 & $\begin{array}{l}\text { Desperanti peccatori a moriente } \\
\text { Jesu restituta vita. Das ist: Das durch } \\
\text { den Todt Jesu dem verzweifflenden } \\
\text { Sünder wider beygebrachte Leben }\end{array}$ & $\begin{array}{l}\text { Brünn, } \\
\text { Nikolauskirche / --- }\end{array}$ & J. G. Reinhardt & CZ-R (dt.) \\
\hline 1723 & $\begin{array}{l}\text { Cantata sacra, in cui si considera la de- } \\
\text { posizione dalla croce, dell'amorisissimo } \\
\text { Redentor Nostro Gesù }\end{array}$ & Brünn / [WHS] & ? & CZ-R (it./dt.) \\
\hline 1724 & $\begin{array}{l}\text { Componimenti sacri da cantarsi } \\
\text { nella sera del Venerdi Santo, ed in } \\
\text { quella della Domenica di Pasqua di } \\
\text { Resurrezione }\end{array}$ & Brünn / WHS & $?$ & $\begin{array}{l}\text { CZ-Bu, CZ-R (it./ } \\
\text { dt.) }\end{array}$ \\
\hline 1724 & $\begin{array}{l}\text { Ruhmwürdiger Cron- und Ehren- } \\
\text { Streitt, anlagend den grossen Hei- } \\
\text { ligen stummen Wohlredner und } \\
\text { wohlredenten Stummen S. Joannem } \\
\text { Nepomucenum }\end{array}$ & $\begin{array}{l}\text { Brünn, Petersberg } \\
\text { / --- }\end{array}$ & G. Porsile / ? & $\begin{array}{l}\text { CZ-R (3x), CZ-OLu } \\
\text { (dt.) }\end{array}$ \\
\hline 1725 & $\begin{array}{l}\text { Il rè del dolore in Giesù Cristo Signor } \\
\text { nostro coronato di spine }\end{array}$ & Brünn / --- & $\begin{array}{l}\text { A. Caldara / } \\
\text { P. Pariati } \\
\end{array}$ & CZ-R (it., dt.) \\
\hline 1725 & II sacrificio di Gefte & Brünn / --- & $\begin{array}{l}\text { G. Porsile / G. } \\
\text { Salio }\end{array}$ & CZ-R (it.+dt.res.) \\
\hline 1726 & Il peccato di Adamo & Brünn / [WHS] & [pasticcio] & $\begin{array}{l}\text { CZ-R (it.+dt.res.) / } \\
\text { CZ-Bm (Fragment) }\end{array}$ \\
\hline 1726 & $\begin{array}{l}\text { Per crucem Jesu fit desperanti vi- } \\
\text { tae restitutio, das ist: Das durch das } \\
\text { Creutz Jesu dem verzweiffelten Sün- } \\
\text { der wieder beygebrachene Leben }\end{array}$ & $\begin{array}{l}\text { Olmütz, } \\
\text { Kapuzinerkirche / --- }\end{array}$ & J. G. Reinhardt & GB-Lbl (dt.) \\
\hline
\end{tabular}




\begin{tabular}{|c|c|c|c|c|}
\hline Jahr & Titel & Ort / Auftraggeber & $\begin{array}{l}\text { Komponist / } \\
\text { Librettist }\end{array}$ & $\begin{array}{l}\text { Libretto (Sprache) } \\
\text { / Musik }\end{array}$ \\
\hline 1726 & $\begin{array}{l}\text { Unüberwindliche Verschwiegenheit } \\
\text { des wunderthätigen Blut-Zeugen } \\
\text { Christi S. Joannis von Nepomuck }\end{array}$ & $\begin{array}{l}\text { Olmütz, } \\
\text { Jesuitenkirche / } \\
\text {--- }\end{array}$ & F. B. Conti & CZ-OLu (dt.) \\
\hline 1727 & Santo Ermenegildo & Brünn / [WHS] & D. Sarrò / ? & CZ-Pu (it.+dt.res.) \\
\hline 1729 & La deposizione dalla croce & Brünn / WHS & $\begin{array}{l}\text { [J. J. Fux / } \\
\text { G. C. Pasquini] }\end{array}$ & CZ-Bu (it.+dt.res.) \\
\hline 1729 & $\begin{array}{l}\text { La speranza consolata da S. Nicolo } \\
\text { vescovo di Mira }\end{array}$ & Brünn / WHS & $?$ & $\begin{array}{l}\text { CZ-OLu (2x) } \\
\text { (it.+dt.res.) } \\
\end{array}$ \\
\hline 1729 & Sant'Alessio & Brünn / WHS & [G. Chiti / ?] & $\begin{array}{l}\text { CZ-OLu (2x) } \\
\text { (it.+dt.res.) }\end{array}$ \\
\hline 1729 & $\begin{array}{l}\text { La santissima annunciazione di Ma- } \\
\text { ria Vergine }\end{array}$ & Brünn / WHS & [A. Caldara / ?] & $\begin{array}{l}\text { CZ-Bam (it.+dt. } \\
\text { res.) }\end{array}$ \\
\hline 1729 & Die Beschuldigte Unschuld & $\begin{array}{l}\text { Olmütz, } \\
\text { Kapuzinerkirche / } \\
\text { JAQ }\end{array}$ & F. A. Míča / & CZ-R (dt.) \\
\hline 1730 & $\begin{array}{l}\text { Bersabea, ovvero II pentimento di } \\
\text { David }\end{array}$ & Brünn / WHS & $\begin{array}{l}\text { G. Reutter / } \\
\text { G. B. Catena }\end{array}$ & $\begin{array}{l}\text { CZ-OLu, CZ-Bu } \\
\text { (it.+dt.res.) }\end{array}$ \\
\hline 1730 & La caduta di Gerico & Brünn / WHS & $\begin{array}{l}\text { A. Caldara / } \\
\text { A. Gargieria }\end{array}$ & $\begin{array}{l}\text { CZ-OLu, CZ-Bu, } \\
\text { I-MOe (it.+dt.res.) }\end{array}$ \\
\hline 1730 & $\begin{array}{l}\text { Il mondo trionfante nella concezio- } \\
\text { ne di Maria sempre Vergine }\end{array}$ & Brünn / WHS & $\begin{array}{l}\text { N. Logroscino / } \\
\text { F. Itto } \\
\end{array}$ & $\begin{array}{l}\text { CZ-OLu, CZ-Bu } \\
\text { (it.+dt.res.) }\end{array}$ \\
\hline 1730 & Morte, e sepoltura di Christo & Brünn / WHS & $\begin{array}{l}\text { A. Caldara / F. } \\
\text { Fozio }\end{array}$ & $\begin{array}{l}\text { CZ-OLu, CZ-Bu } \\
\text { (it.+dt.res.) / D-B }\end{array}$ \\
\hline 1730 & Santa Cecilia & Brünn / WHS & $\begin{array}{l}\text { G. B. Costanzi / } \\
\text { Pastore Arcade }\end{array}$ & $\begin{array}{l}\text { CZ-OLu (it.+dt. } \\
\text { res.) }\end{array}$ \\
\hline 1730 & II trionfo della croce & Brünn / WHS & $\begin{array}{l}\text { G. C. Predieri / } \\
\text { Pastore Arcade } \\
\text { [G. B. Taroni] }\end{array}$ & $\begin{array}{l}\text { CZ-OLu (it.+dt. } \\
\text { res.) / } D-B\end{array}$ \\
\hline 1730 & $\begin{array}{l}\text { Testamentum Salvatoris, Das ist: } \\
\text { Der letzte Willen des Erlösers unsers } \\
\text { Herrns Jesu Christi }\end{array}$ & \begin{tabular}{|l|} 
Brünn, Jakobskirche / \\
Magistrat der könig. \\
Stadt Brünn
\end{tabular} & J. G. Reinhardt & CZ-R (dt.) \\
\hline 1730 & $\begin{array}{l}\text { Ein andächtig-verfastes Oratorium } \\
\text { zu Ehren des grosses Blut-Zeugens } \\
\text { Christi Heil. Joannis von Nepomuck }\end{array}$ & $\begin{array}{l}\text { Brünn, Petersberg / } \\
\text { JMTV }\end{array}$ & [J. G. Orsler] & CZ-R (dt.) \\
\hline 1730 & Die Beschuldigte Unschuld & $\begin{array}{l}\text { Brünn, } \\
\text { Kapuzinerkirche / } \\
\text { JAQ }\end{array}$ & F. A. Míča & CZ-R, CZ-Bu (dt.) \\
\hline 1731 & Cristo nell'orto & Brünn / WHS & $\begin{array}{l}\text { J. J. Fux / } \\
\text { P. Pariati }\end{array}$ & CZ-Bu (it.+dt.res.) \\
\hline 1731 & Giacobbe & Brünn / WHS & $\begin{array}{l}\text { V. M. Gurecký / } \\
\text { G. B. Catena }\end{array}$ & $\begin{array}{l}\text { CZ-OLu, I-Bc, } \\
\text { I-Mb, I-Vnm } \\
\text { (it.+dt.res.) }\end{array}$ \\
\hline 1731 & $\begin{array}{l}\text { La passione di Giesu Cristo Signor } \\
\text { nostro }\end{array}$ & Brünn / WHS & $\begin{array}{l}\text { A. Caldara / } \\
\text { P. Metastasio }\end{array}$ & $\begin{array}{l}\text { CZ-Bu (2x) (it.+dt. } \\
\text { res.) }\end{array}$ \\
\hline 1731 & $\begin{array}{l}\text { L'ultima persecuzione di Saule con- } \\
\text { tro Davidde }\end{array}$ & Brünn / WHS & $\begin{array}{l}\text { F. Peli / } \\
\text { G. Tagliazucchi }\end{array}$ & CZ-R (it.+dt.res.) \\
\hline 1731 & Santa Catterina & Brünn / WHS & $\begin{array}{l}\text { P. G. Sandoni / } \\
\text { Pastore Arcade }\end{array}$ & CZ-Bu (it.+dt.res.) \\
\hline 1731 & $\begin{array}{l}\text { Öfterer Anstoß, des zum Berg Calva- } \\
\text { riae im Geist auffsteigenden Wan- } \\
\text { dersmann }\end{array}$ & $\begin{array}{l}\text { Brünn, } \\
\text { Kapuzinerkirche / } \\
\text { JAQ }\end{array}$ & F. A. Míča & CZ-Bu, CZ-R (dt.) \\
\hline
\end{tabular}




\begin{tabular}{|c|c|c|c|c|}
\hline Jahr & Titel & Ort / Auftraggeber & $\begin{array}{l}\text { Komponist / } \\
\text { Librettist }\end{array}$ & $\begin{array}{l}\text { Libretto (Sprache) } \\
\text { / Musik }\end{array}$ \\
\hline 1731 & $\begin{array}{l}\text { Ein andächtig-verfastes Oratorium } \\
\text { zu Ehren des grossen Blut-Zeugens } \\
\text { Christi Heiligen Joannis von Nepo- } \\
\text { muck }\end{array}$ & Olmütz / [JMTV] & J. G. Orsler & CZ-OLu (dt.) \\
\hline 1731 & $\begin{array}{l}\text { Canon, vitae canonicae prodigiosus } \\
\text { orbis Thaumaturgus }\end{array}$ & Olmütz, Kathedral & J. R. Keller & CZ-OLu (lat.) \\
\hline 1732 & $\begin{array}{l}\text { II martirio di S. Giovanni Nepomu- } \\
\text { ceno }\end{array}$ & Brünn / WHS & $\begin{array}{l}\text { N. Porpora / } \\
\text { Marchese di S. } \\
\text { Christina }\end{array}$ & $\begin{array}{l}\text { CZ-OLu, I-Mb } \\
\text { (it.+dt.res.) / } \\
D-B\end{array}$ \\
\hline 1732 & $\begin{array}{l}\text { La santissima annunziazione di Ma- } \\
\text { ria sempre Vergine }\end{array}$ & Brünn / WHS & $\begin{array}{l}\text { L. Vinci / Pastore } \\
\text { Arcade }\end{array}$ & $\begin{array}{l}\text { CZ-OLu (it.+dt. } \\
\text { res.) }\end{array}$ \\
\hline 1732 & $\begin{array}{l}\text { Il trionfo della virtù in S. Nicolò di } \\
\text { Bari }\end{array}$ & Brünn / WHS & $\begin{array}{l}\text { L. Leo / Pastore } \\
\text { Arcade [S. } \\
\text { Stampiglia] }\end{array}$ & $\begin{array}{l}\text { CZ-OLu (it.+dt. } \\
\text { res.) }\end{array}$ \\
\hline 1733 & S. Elena al Calvario & Brünn / WHS & $\begin{array}{l}\text { L. Leo / } \\
\text { P. Metastasio }\end{array}$ & SI-Lsk (it.+dt.res.) \\
\hline 1733 & Die Beschuldigte Unschuld & $\begin{array}{l}\text { Brünn, } \\
\text { Kapuzinerkirche / --- }\end{array}$ & J. G. Orsler & CZ-R (dt.) \\
\hline 1734 & S. Francesco di Paola & Brünn / WHS & $\begin{array}{l}\text { V. M. Gurecký / } \\
\text { A. Fontanelli }\end{array}$ & $\begin{array}{l}\text { CZ-Bu }(2 x)(\text { it. }+\mathrm{dt} . \\
\text { res.), I-Bc }\end{array}$ \\
\hline 1734 & $\begin{array}{l}\text { Die Heil. Helena auf dem Calvari- } \\
\text { Berg }\end{array}$ & $\begin{array}{l}\text { Brünn, } \\
\text { Kapuzinerkirche / } \\
\text { JAQ }\end{array}$ & $\begin{array}{l}\text { F. A. Míča / } \\
\text { P. Metastasio }\end{array}$ & CZ-R (dt.) \\
\hline 1734 & $\begin{array}{l}\text { Das Leyden und Sterben des } \\
\text { Heylands Jesu Christi }\end{array}$ & $\begin{array}{l}\text { Znaim / C. J. R. de } \\
\text { Souches }\end{array}$ & $\begin{array}{l}\text { J. J. Knefrle / F. } \\
\text { A. Neumann }\end{array}$ & $\mathrm{CZ}-\mathrm{Bu}$ (dt.) \\
\hline 1736 & Il candor vendicato di Nostra Signora & Brünn / WHS & $\begin{array}{l}\text { G. Porta / A. } \\
\text { Cassetti }\end{array}$ & CZ-HR (it.+dt.res.) \\
\hline 1736 & Gioas, re di Giuda & Brünn / WHS & $\begin{array}{l}\text { V. M. Gurecký / } \\
\text { P. Metastasio } \\
\end{array}$ & $\begin{array}{l}\text { CZ-OLu, CZ-Pnm } \\
\text { (it.+dt.res.) }\end{array}$ \\
\hline 1736 & S. Elena al Calvario & $\begin{array}{l}\text { Brünn, Jakobskirche } \\
\text { / JAQ }\end{array}$ & $\begin{array}{l}\text { A. Caldara / } \\
\text { P. Metastasio } \\
\end{array}$ & CZ-R (it.+dt.res.) \\
\hline 1736 & Il martirio della madre de'Macabei & $\begin{array}{l}\text { Brünn, } \\
\text { Michaelerkirche / } \\
\text { JAQ }\end{array}$ & F. B. Conti & CZ-Bu (it.+dt.res.) \\
\hline 1736 & $\begin{array}{l}\text { Öfterer Anstoß, des zum Berg Calva- } \\
\text { riae im Geist auffsteigenden Wand- } \\
\text { resmann }\end{array}$ & $\begin{array}{l}\text { Olmütz, } \\
\text { Kapuzinerkirche / } \\
\text { JAQ }\end{array}$ & F. A. Míča & $\begin{array}{l}\text { CZ-SOKA Přerov } \\
\text { (dt.) }\end{array}$ \\
\hline 1736 & S. Giovanni Battista & Holleschau / FAR & A. Caldara & $\begin{array}{l}\text { CZ-KRa (it.) } \\
\text { (verschollen) }\end{array}$ \\
\hline 1737 & San Vicenzo Fererio & Brünn / WHS & $\begin{array}{l}\text { G. Bonno / } \\
\text { Pastore Arcade }\end{array}$ & $\begin{array}{l}\text { CZ-Pnm, CZ-R } \\
\text { (it.+dt.res.) }\end{array}$ \\
\hline 1737 & $\begin{array}{l}\text { La passione di Giesu Christo Signore } \\
\text { nostro }\end{array}$ & Brünn / WHS & $\begin{array}{l}\text { G. Venturelli / } \\
\text { P. Metastasio }\end{array}$ & $\begin{array}{l}\text { CZ-Pnm (it.+dt. } \\
\text { res.) }\end{array}$ \\
\hline 1737 & La donna forte & Brünn / WHS & $\begin{array}{l}\text { L. Vinci / C. } \\
\text { Benassai }\end{array}$ & $\begin{array}{l}\text { CZ-Pnm (it.+dt. } \\
\text { res.) }\end{array}$ \\
\hline 1737 & Daniello & Brünn / WHS & F. Araja / A. Zeno & $\begin{array}{l}\text { CZ-Pnm (it.+dt. } \\
\text { res.) }\end{array}$ \\
\hline 1737 & $\begin{array}{l}\text { La conversione di S. Pellegrino La- } \\
\text { ziosi }\end{array}$ & Brünn / WHS & $\begin{array}{l}\text { N. R. Redi / } \\
\text { Pastore Arcade }\end{array}$ & $\begin{array}{l}\text { CZ-Pnm (it.+dt. } \\
\text { res.) }\end{array}$ \\
\hline
\end{tabular}




\begin{tabular}{|c|c|c|c|c|}
\hline Jahr & Titel & Ort / Auftraggeber & $\begin{array}{l}\text { Komponist / } \\
\text { Librettist }\end{array}$ & $\begin{array}{l}\text { Libretto (Sprache) } \\
\text { / Musik }\end{array}$ \\
\hline 1738 & David umiliato & Brünn / WHS & F. Araia / A. Zeno & CZ-Bk (it.+dt.res.) \\
\hline 1738 & $\begin{array}{l}\text { Il giusto afflitto nella persona di } \\
\text { Giobbe }\end{array}$ & Brünn / WHS & $\begin{array}{l}\text { G. Pera / G. C. } \\
\text { Pasquini }\end{array}$ & I-Mb (it.+dt.res.) \\
\hline 1738 & $\begin{array}{l}\text { La divina pietà trionfante } \\
\text { nell'imaculata concezione di Maria } \\
\text { Vergine }\end{array}$ & Brünn / WHS & $\begin{array}{l}\text { N. Porpora / } \\
\text { Pastore Arcade }\end{array}$ & $\begin{array}{l}\text { CZ-OLu (it.+dt. } \\
\text { res.) }\end{array}$ \\
\hline 1740 & $\begin{array}{l}\text { Der durch die Gerechtigkeit ver- } \\
\text { dammte und von der Göttlichen Lie- } \\
\text { be erlöste Sünder }\end{array}$ & $\begin{array}{l}\text { Brünn, Jakobskirche } \\
\text { / --- }\end{array}$ & [V. M. Gurecký?] & CZ-Pnm (dt.) \\
\hline 1741 & $\begin{array}{l}\text { La vittima d'amore o sia La morte si } \\
\text { Christo S. N. }\end{array}$ & Brünn / --- & $\begin{array}{l}\text { J. Umstatt / } \\
\text { Pastore Arcade } \\
\text { [F. Torti] }\end{array}$ & CZ-Bm (it.+dt.res.) \\
\hline 1745 & $\begin{array}{l}\text { Das Durch Treu, und Andacht ge- } \\
\text { crönte Jahr-Hundert (Oratorio per la } \\
\text { Coronatione B. V. M.) }\end{array}$ & Brünn / --- & J. Umstatt & $\begin{array}{l}\text { CZ-Bu (dt.) / } \\
\text { CZ-Bm }\end{array}$ \\
\hline
\end{tabular}

Jana Spáčilová (janasp@seznam.cz), Oddělení dějin hudby, Moravské zemské muzeum, Brno.

\section{ABSTRACT \\ UNKNOWN ORATORIOS BY NAPLES COMPOSERS IN BRNO BEFORE 1740}

An unprecedented upsurge of the Italian oratorio was experienced in Brno, South Moravia, in 1720 s and 1730s, testified by 49 extant oratorio libretti of local origin. Productions of these musical pieces were organized mainly by Count Wolfgang Hannibal Schrattenbach, Olomouc bishop and former viceroy of Naples; hence the considerable number of otherwise unknown compositions by Neapolitan composers on the repertoire (Porpora, Vinci etc.). On the basis of a number of case studies, the present paper aims at describing the textual history of the selected librettos and scores, offering a hypothesis concerning their origin, and outlining the generic overlap between opera and oratorio as musical genres. Attached is the list of all known oratorios produced in Brno before 1740 .

\section{Key words}

libretto, oratorio, pasticcio, borrowed aria, Brno, Olomouc, Schrattenbach

\section{Bibliography}

DOKOUPIL, Vladislav. Soupis brněnských tisků. Staré tisky do roku 1800, Brno: Státní vědecká knihovna, 1978.

EITNER, Robert. Biographisch-Bibliographisches Quellen-Lexikon der Musiker und Musikgelehrten, Leipzig, 1900-1904.

FUKAČ, Jiří. Křižovnický hudební inventář. Př́spěvek k poznáni křižovnické hudební kultury a jejiho mista v hudebnim životě barokni Prahy, Diplomarbeit, Brno, 1959.

GASPARI, Gaetano. Catalogo della Biblioteca del Liceo Musicale di Bologna. Bd 5, Libretti d'opera in musica, ed. Ugo Sesini. Bologna, 1943. 
GLÖCKNER, Andreas. Die ältere Notenbibliothek der Thomasschule zu Leipzig. Verzeichniss eines weitgehend verschollenen Bestands. Hildesheim: Olms, 2011.

KAČIC, Ladislav. Joseph Umstatt (1711-1762) zwischen Barock und Klassik: Bemerkungen zur Stilentwicklung eines mitteleuropäischen Komponisten. In Zur Geschische und Aufführungspraxis der Musik des 16.-18. Jahrhunderts in Mittel- und Osteuropa, Bratislava, 2013, S. 201-215.

KAMPER, Otakar. Hudebni Praha v 18. věku. Praha, 1936.

KAPSA, Václav. Hudebníci hraběte Morzina. Přispěvek $k$ dějinám šlechtických kapel v Čechách $v$ době baroka. Praha: Kabinet hudební historie EÚ AV ČR, 2010.

MACEK, Ondřej - SPÁČILOVÁ, Jana. Nová zjištění k latinské karnevalové opeře Facetum Musicum / Musicalisches Kurtzweil-Spiel (Osek 1738). Hudební věda, 2011, 48, Nr. 2-3, S. 143-160.

PEGAH, Rashid-S. Ein Argippo-Pasticcio. Studi Vivaldiani, 2011, 11, S. 63-76.

PERUTKOVÁ, Jana - MANAS, Vladimír. Pašijové oratorium ve Znojmě roku 1734 - příspěvek k poznání hudebního života na Moravě. Opus musicum, 2012, 44, Nr. 3, S. 6-13.

PERUTKOVÁ, Jana. František Antonín Mǐča ve službách hraběte Questenberga a italská opera v Jaroměricích. Praha: KLP, 2011.

SEHNAL, Jiří. Die Adeligen Musikkapellen im 17. und 18. Jahrhundert in Mähren. In Studies in Music History presented to H. C. Robbins Landon on his 70. Birthday, London, 1996, S. 195-217.

SEHNAL, Jiří. Hudební literatura zámecké knihovny v Kroměřiži. Gottwaldov, 1960.

SEHNAL, Jiř́i. Kapela olomouckého biskupa Leopolda Egka (1758-1760) a její repertoár. Časopis Moravského musea, 1965, 50, S. 203-230.

SEHNAL, Jiří. Nové poznatky k dějinám hudby na Moravě v 17. a 18. století. Časopis Moravského musea, 1975, 60, S. 159-180.

SPÁČILOVÁ, Jana. Chrámová hudba v Kroměřǐži v roce 1731. Olomoucký biskup Schrattenbach a hudba vrcholného baroka [3]. Opus musicum, 2005, Nr. 3, S. 39-45.

SPÁČILOVÁ, Jana. Händel v barokní Praze. Dosud neznámé doklady provozování Händelovy hudby v chrámu pražských křižovníků s červenou hvězdou v první polovině 18. století. Musicologica Brunensia, SPFFBU, H 38-40 (2003-2005). Brno 2006, S. 237-244.

SPÁČILOVÁ, Jana. Hudba na dvoře olomouckého biskupa Schrattenbacha (1711-1738). Př́spěvek k libretistice barokni opery a oratoria. Diss. MU Brno 2006.

SPÁČILOVÁ, Jana. Das „Oratorio di S. Giovanni Nepomoceno“ von Antonio Caldara im Kontext der Nepomuk-Oratorien in den 20er Jahren des 18. Jahrhunderts. Musicologica Austriaca, 2009, 28, S. $145-160$.

SPÁČILOVÁ, Jana. Brněnská opera Argippo z roku 1733 ve světle nových výzkumů. Opus musicum, 2013, 45, Nr. 2, S. 6-21.

SPÁČILOVÁ, Jana. Contiho moteto k poctě svatých Cyrila a Metoděje. Vlastivědný věstník morav$s k y ́, 2013,65$, Nr. 2, S. 140-146.

SPÁČILOVÁ, Jana. Kirchenmusik Wiener Komponisten in Mähren in der ersten Hälfte des 18. Jahrhunderts. In Sakralmusik im Habsburgerreich 1570-1770, Wien, 2013, S. 285-300.

SPÁČILOVÁ, Jana. Niccolò Porpora a jeho opera Siface: vítězství neapolského stylu v českých zemích. Opus musicum, 2013, 45, Nr. 3, S. 36-42. SPÁČILOVÁ, Jana. K provozování oratorií v Brně v 1. polovině 18. století. Opus musicum, 2013, 45, Nr. 6, S. 6-16.

SPÁČILOVÁ, Jana. Nově identifikované hudební materiály k oratoriu Il peccato di Adamo (Brno 1726). In Hudba v Olomouci a na střední Moravě I. In memoriam Vladimír Hudec, Olomouc, 2007, S. 253-266.

SPÁČILOVÁ, Jana. Sant'Elena al Calvario: Leo, Míča, Caldara nebo Conti? Příspěvek k historii oratoria v českých zemích doby baroka. Opus musicum, 2009, 41, Nr. 3, S. 25-29.

SPÁČILOVÁ, Jana. Die Rezeption der italienischen Oper am Hofe des Olmützer Bischofs Schrattenbach. In The Eighteenth-Century Italian Opera Seria: Metamorphoses of the Opera in the Imperial Age [Colloquia Musicologica Brunensia, 42, 2007], Praha: KLP, 2013, S. 75-88.

SPÁČILOVÁ, Jana. Nové poznatky k hudbě na dvoře olomouckého biskupa Schrattenbacha. Musicologica Brunensia, 2010, Nr. 1-2, S. 198-206. 
STOCKIGT, Janice. Italian Composers Listed in the „Catalogo 1765“ (,Schürer-Katalog“) of the Dresden Hofkirche. Pergolesi Studies, 2012, 8, S. 171-198.

STRAKOVÁ, Theodora. Hudebníci na collaltovském panství. Časopis Moravského musea, 1966, 51, S. 231-268, hier auf S. 248.

STROHM, Reinhard. Argippo in „Germania“. Studi Vivaldiani, 2008, 8, S. 111-127. 
